\title{
Applications of synchrotron in soil science
}

V.P. Gadha and V. Thulasi

CORRESPONDING AUTHOR :

V.P. Gadha, College of Horticulture, Vellanikkara, Thrissur (Kerala)

India

Co-authors :

V. Thulasi, Regional Agricultural Research Station, Pattambi (Kerala) India

Email: thulasi.v@kau.in
Received : $16.10 .2020 ;$ Accepted : 24.11 .2020

\section{Summary}

Synchrotron radiations (SR) are emerging as a real-time probing tool for the wide range of applied sciences. Since the beginning of 1990s, synchrotron-based techniques have become increasingly employed in various fields of life science. The unique properties of Synchrotron radiations break the limits to characterize the material properties than previous laboratory based techniques. The use of SR in soil sciences also has increased dramatically in the last decade. SR techniques are used to assess soil physical, chemical and biological properties. Besides that SR techniques are also used in soil pollution studies and rhizosphere science. So this paper intends to explain about the instrument synchrotron, its techniques used in soil science and applications in soil science. Furthermore the paper tries to elucidate a few relevant researches in soil science which involves SR techniques.

Key words : Synchrotron radiations, Laboratory based techniques

How to cite this article : Gadha, V.P. and Thulasi, V. (2020). Applications of synchrotron in soil science. Asian J. Soil Sci., 15(2): 111-115: DOI : 10.15740/HAS/AJSS/15.2/111-115. Copyright@2020: Hind Agri-Horticultural Society. 